\title{
Electrophysiological evidence for the presence of NR2C subunits of $N$-methyl-D-aspartate receptors in rat neurons of the nucleus tractus solitarius
}

V. Baptista, W.N. Ogawa, J.F. Aguiar and W.A. Varanda
Departamento de Fisiologia, Faculdade de Medicina de Ribeirão Preto, Universidade de São Paulo, Ribeirão Preto, SP, Brasil

\author{
Correspondence \\ W.A. Varanda \\ Departamento de Fisiologia \\ FMRP, USP \\ Av. Bandeirantes, 3900 \\ 14049-900 Ribeirão Preto, SP \\ Brasil \\ Fax: +55-16-633-0017 \\ E-mail: wvaranda@fmrp.usp.br \\ V. Baptista was the recipient of a \\ FAPESP fellowship, W.N. Ogawa was \\ the recipient of a CAPES fellowship \\ and the research of W.A. Varanda \\ was supported by FAPESP.
}

Received March 3, 2004 Accepted October 1, 2004

\begin{abstract}
The nucleus tractus solitarius (NTS) plays an important role in the control of autonomic reflex functions. Glutamate, acting on $\mathrm{N}$-methylD-aspartate (NMDA) and non-NMDA ionotropic receptors, is the major neurotransmitter in this nucleus, and the relative contribution of each receptor to signal transmission is unclear. We have examined NMDA excitatory postsynaptic currents (NMDA-EPSCs) in the subpostremal NTS using the whole cell patch clamp technique on a transverse brainstem slice preparation. The NMDA-EPSCs were evoked by stimulation of the solitary tract over a range of membrane potentials. The NMDA-EPSCs, isolated pharmacologically, presented the characteristic outward rectification and were completely blocked by $50 \mu \mathrm{M}$ DL-2-amino-5-phosphonopentanoic acid. The $I-V$ relationship of the NMDA response shows that current, with a mean ( \pm SEM) amplitude of $-41.2 \pm 5.5 \mathrm{pA}$, is present even at a holding potential of $-60 \mathrm{mV}$, suggesting that the NMDA receptors are weakly blocked by extracellular $\mathrm{Mg}^{2+}$ at near resting membrane potentials. This weak block can also be inferred from the value of $0.67 \pm 0.17$ for parameter $\delta$ obtained from a fit of the Woodhull equation to the $I-V$ relationship. The maximal inward current measured on the $I-V$ relationship was at $-38.7 \pm 4.2 \mathrm{mV}$. The decay phase of the NMDA currents was fitted with one exponential function with a decay time constant of $239 \pm 51$ and $418 \pm 80 \mathrm{~ms}$ at a holding potential of -60 and $+50 \mathrm{mV}$, respectively, which became slower with depolarization (e-fold per $145 \mathrm{mV}$ ). The biophysical properties of the NMDA receptors observed in the present study suggest that these receptors in the NTS contain NR2C subunits and may contribute to the synaptic signal integration.
\end{abstract}

The nucleus tractus solitarius (NTS) is the primary site for a variety of peripheral sensory inputs including those of cardiovascular, respiratory, gustatory, and gastrointestinal origins (1). Most of the afferent fibers involved in the control of cardiovascular and respiratory functions terminate around the
Key words

- Nucleus tractus solitarius

- Electrophysiology

- Synapse

- NMDA receptors

- NR2C subunits obex and caudal to it (2), in the subpostremal NTS (3). Although there are a large variety of neurotransmitters and neuromodulators within the NTS, glutamate and GABA are considered to be the principal neurotransmitters (4-6). It is accepted that glutamate is the neurotransmitter released by the first-order 
visceral afferent fibers $(6,7)$ and that it acts on $\mathrm{N}$-methyl-D-aspartate (NMDA) and nonNMDA ionotropic receptors in second-order neurons within the NTS $(5,8)$. The relative role of NMDA and non-NMDA receptors in synaptic transmission in the NTS is not well understood. Several lines of evidence indicate that non-NMDA receptors play the predominant role in synaptic transmission within the NTS (9) while activation of NMDA receptors may modulate the autonomic signal transmission by depolarizing second order neurons subjected to high frequency or convergent stimulation (5). The specific type of NMDA receptor determines the extent of its involvement in the synaptic transmission process. NMDA receptors consist of hetero-oligomers of the NR1, NR2ANR2D and NR3A, NR3B subunits $(10,11)$. The NR1 subunit, expressed ubiquitously in the central nervous system (CNS), confers the essential functions of the NMDA receptors. In contrast, other subunits show more limited expression and confer a functional diversity (11). The NMDA receptor function depends on agonist binding and membrane potential, representing a unique feature among the ligand-gated ion channels. The voltage dependence of the NMDA receptors is mainly due to a voltage-dependent block by extracellular $\mathrm{Mg}^{2+}(12,13)$ and this property dominates their physiological role (1113).

To gain insight into the glutamatergic transmission in the subpostremal NTS, we have analyzed the NMDA postsynaptic currents evoked by solitary tract stimulation. A transverse slice preparation of the medulla oblongata containing the subpostremal NTS was obtained from 30- to 35-day-old Wistar rats of either sex and used in the experiments. The animals were anesthetized with Nembutal $(50 \mathrm{mg} / \mathrm{kg}$, ip). Following decapitation and craniotomy, the brain and upper cervical spinal cord were removed and submerged in ice-cold $\left(2-3^{\circ} \mathrm{C}\right)$ artificial cerebrospinal fluid (aCSF), $\mathrm{pH}$ 7.35-7.4, equili- brated with carbogen $\left(95 \% \mathrm{O}_{2}, 5 \% \mathrm{CO}_{2}\right)$. The aCSF contained $122 \mathrm{mM} \mathrm{NaCl}, 2.5 \mathrm{mM}$ $\mathrm{KCl}, 1.0 \mathrm{mM} \mathrm{MgCl}_{2}, 2.0 \mathrm{mM} \mathrm{CaCl}_{2}, 25 \mathrm{mM}$ $\mathrm{NaHCO}_{3}, 1.25 \mathrm{mM} \mathrm{NaH}_{2} \mathrm{PO}_{4}$, and $25 \mathrm{mM}$ glucose, with osmolality of $305-310 \mathrm{mOsm} /$ $\mathrm{kg} \cdot \mathrm{H}_{2} \mathrm{O}$, and was continuously gassed with carbogen. After dissection, the brainstem was glued with cyanoacrylate glue to an Lshaped agar block (4\% agar in aCSF) and placed on the stage of a vibrating tissue slicer (MA756, Campden Instruments, Leicester, England). Two transverse slices (300 $\mu \mathrm{m})$ containing the area postrema were obtained from each animal and incubated in aCSF for $60 \mathrm{~min}$ at $32^{\circ} \mathrm{C}$. A single slice was transferred to the recording chamber on the stage of an upright microscope (E600 Nikon Inc., Tokyo, Japan) and held in place with a nylon net mounted on a platinum wire. The chamber was continuously perfused with aCSF at a rate of $2-3 \mathrm{ml} / \mathrm{min}$, driven by gravity. All drugs were applied at known concentrations with the perfusion solution. Experiments were performed at room temperature $\left(23-25^{\circ} \mathrm{C}\right)$. Strychnine was purchased from Sigma (St. Louis, MO, USA), DL-2-amino-5-phosphonopentanoic acid (DL-AP5), 6,7-dinitroquinoxaline-2,3 dione (DNQX), trans-2-carboxy-5,7-dichloro-4phenylaminocarbonyl amino-1,2,3,4-tetrahydroquinoline (L-689-560) and bicuculline methochloride were purchased from Tocris Cookson Inc. (Ellisville, MO, USA). All other salts were purchased from Sigma. Efforts were made to minimize the number of animals used and their suffering in accordance with the Guide for the Care and Use of Laboratory Animals of the Faculty of Medicine of Ribeirão Preto, USP.

Patch pipettes were pulled from borosilicate glass tubing (Sutter Instrument Co., Novato, CA, USA) on a P-97 puller (Sutter Instrument Co.) and fire polished on a microforge (MF-83; Narishige, Tokyo, Japan). The internal solution was $130 \mathrm{mM}$ CsF, $10 \mathrm{mM} \mathrm{NaCl}, 1 \mathrm{mM} \mathrm{MgCl} 2,3 \mathrm{mM} \mathrm{K}-$ ATP, 10 mM EGTA, 10 mM HEPES, pH 
adjusted to 7.3 with $\mathrm{CsOH}$, and osmolality of 295-305 mOsm $/ \mathrm{kg} . \mathrm{H}_{2} \mathrm{O}$. The reference electrode was an $\mathrm{Ag} / \mathrm{AgCl}$ wire connected to the extracellular solution via an agar bridge (2.5\% in the internal solutions). When filled with the above solution the pipettes had a resistance of 4-8 $\mathrm{M} \Omega$. Junction potentials were of the order of $10 \mathrm{mV}$ and these were taken into account in the results shown. Cells were approached by the 'blind patch' method and seal resistances in excess of $5 \mathrm{G} \Omega$ were obtained prior to entering the whole-cell configuration. The average access resistance, was $18.4 \pm 0.4 \mathrm{M} \Omega(\mathrm{N}=40$ cells $)$ and was corrected by $70-80 \%$. Recordings were obtained with an EPC-7 (List Medical, Darmstadt, Germany) patch clamp amplifier. Whole-cell currents and voltages were lowpass filtered at $3 \mathrm{kHz}$ ( 8 pole Bessel filter LPF8; Warner Instruments Corp., Hamden, CT, USA) digitized at $10 \mathrm{kHz}$ by a computer driven A/D converter (Digidata 1200B; Axon Instruments, Foster City, CA, USA), and stored on the hard disk using the pClamp6 software (Axon Instruments). Data were analyzed off-line using the MiniAnalysis program (Synaptosoft, New Jersey, NJ, USA), Clampfit or Axoscope (Axon Instruments). Synaptic responses of the NTS neurons were evoked by electrical stimulation $(15 \mathrm{~V}, 50$ $100 \mu \mathrm{s}, 0.2-0.5 \mathrm{~Hz}$, stimulus isolation unit DS2A - Digitimer Ltd., Garden City, England) delivered by a twisted pair platinum electrode $(100 \mu \mathrm{m}$ in diameter) positioned on the ipsilateral solitary tract under visual control. The $I-V$ relationship of NMDA receptors-excitatory postsynaptic currents (NMDAR-EPSCs) was fitted by the following equation:

$$
I=\frac{\left[a g_{\max }\left(V-V_{R}\right)\right]}{\left(a+\left[M g^{2+}\right]_{0} e^{-V \delta z F / R T}\right)}
$$

where $V$ is the holding potential, $V_{R}$ is the reversal potential, $g_{\max }$ the maximal conductance measured at holding potentials between +10 and $+50 \mathrm{mV}, a$ represents the dissocia- tion constant in the absence of transmembrane voltage, $\delta$ is the fraction of the membrane voltage at the blocking site and gives the voltage dependence of $\mathrm{Mg}^{2+}$ binding, and $R, T, z$, and $F$ have their usual meaning. The decay time constants or the rise time, taken as the time from the onset to the peak of the response of NMDA receptor currents, as a function of membrane potential, was fitted by Equation 2:

$$
\tau_{(V)}=\frac{1}{B e^{A V}} \quad \text { Eq. } 2
$$

where $A$ and $B$ are constants. The pooled data are reported as the mean \pm SEM and statistical significance between values $(\mathrm{P}<$ $0.05)$ was determined by the Student $t$-test.

The NMDA-evoked EPSCs were isolated by perfusing the preparation with $5 \mu \mathrm{M}$ DNQX, $5 \mu \mathrm{M}$ strychnine and $50 \mu \mathrm{M}$ bicuculline to block non-NMDA, glycine and $\mathrm{GABA}_{\mathrm{A}}$ receptors, respectively (Figure 1A). The remaining response (NMDA component) was completely blocked by $50 \mu \mathrm{M} \mathrm{DL}$ AP5 (Figure 1A, inset). The NMDAR-EPSC rise times showed a remarkable variability between cells (Figure 1C). The decay times of the NMDA-EPSCs were clearly dependent on the membrane voltage, being prolonged by depolarization in an exponential manner (Figure 1D). The decay time constants $\left(\tau_{\mathrm{NMDA}}\right)$ at -70 and $+50 \mathrm{mV}$ were statistically different $(\mathrm{P}<0.05)$. This voltagedependence of the $\tau_{\mathrm{NMDA}}$ has also been observed in other CNS regions $(14,15)$. Considering the reaction between the neurotransmitter and the closed receptor and the subsequent opening of the channel as a simple first-order chemical reaction, the relationship between the decay time constant and the membrane potential could be fitted with the Equation 2. Thus, the values of the $\tau_{\mathrm{NMDA}}$ plotted against voltage on a semi-logarithmic plot fall close to a straight line (Figure 1D). Therefore, the $\tau_{\mathrm{NMDA}}(\mathrm{V})$ apparently obeys the theoretical exponential relation expected from Equation 2, and increases $e$ - 
fold per $145 \mathrm{mV}$.

The $I-V$ relationship of the NMDA response has a characteristic " $J$ " shape with a region of negative slope conductance for voltages more negative than $-40 \mathrm{mV}$, where $\mathrm{Mg}^{2+}$ block of the NMDA receptor channel is evident (Figure 1B, $\mathrm{N}=5$ ). In order to estimate the sensitivity of the NMDA receptor to $\mathrm{Mg}^{2+}$ block, the $\mathrm{I}-\mathrm{V}$ curves obtained from 5 subpostremal NTS neurons were fitted by Equation 1 (Figure 1B). This equation
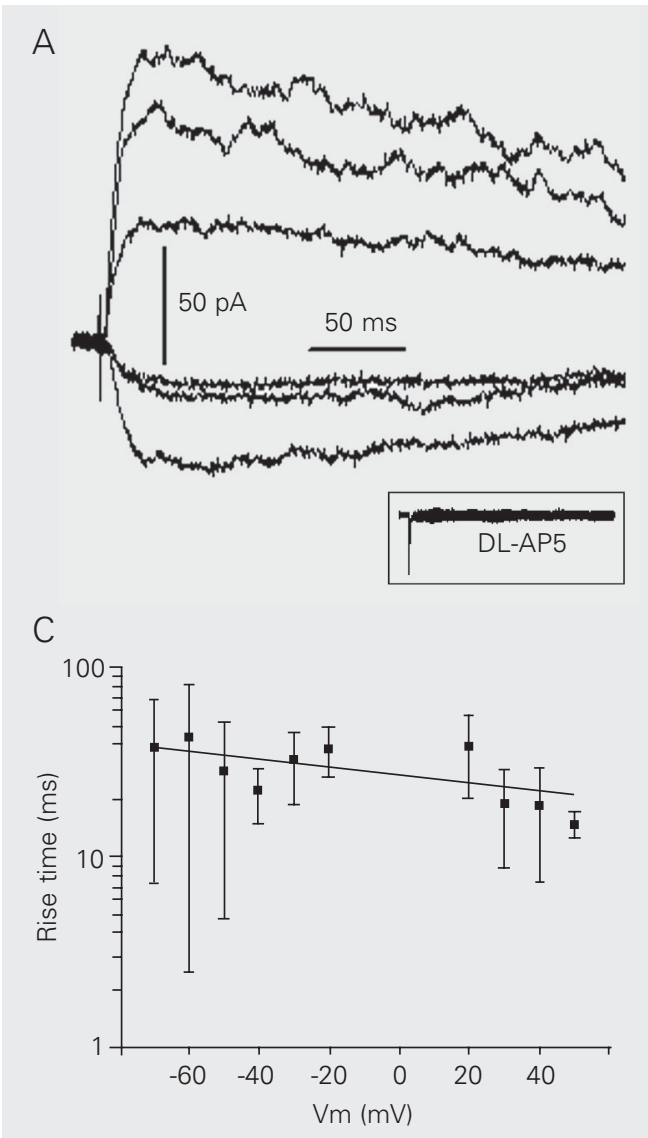

assumes a model where $\mathrm{Mg}^{2+}$ ions block the open channel at a site within the membrane electrical field (16-18). The reversal potential obtained from the fit was $-2.1 \pm 7.3 \mathrm{mV}$. The maximal slope conductance

$$
\left(g_{\max }=\frac{d l}{d V}\right)
$$

derived from the linear range of the $I-V$ relationships (from +10 to $+50 \mathrm{mV}$ ) was 3.4

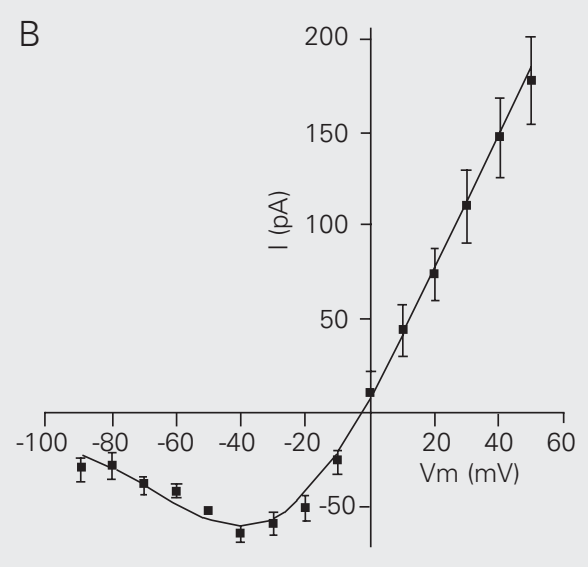

D

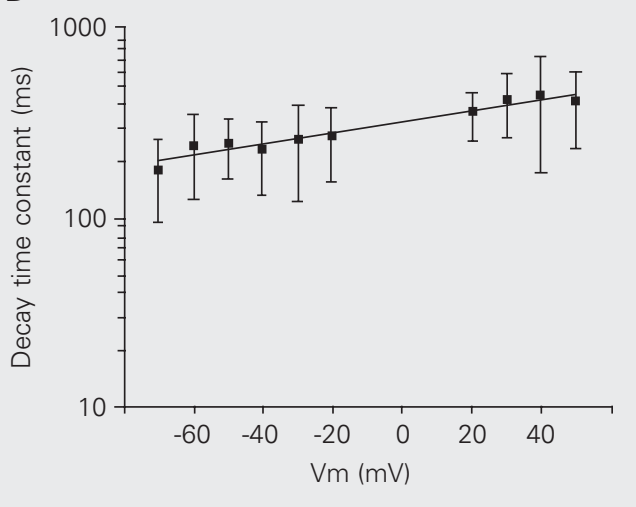

Figure 1. $N$-methyl-D-aspartate (NMDA) receptor-mediated currents recorded from secondary neurons of the nucleus tractus solitarius of the rat. $A$, Pharmacological isolation of the NMDA excitatory postsynaptic currents by perfusion with bicuculline $(50 \mu \mathrm{M})$, strychnine $(5 \mu \mathrm{M})$ and DNQX $(5 \mu \mathrm{M})$. Holding potentials varied from -90 to +50 $\mathrm{mV}$ in $10-\mathrm{mV}$ steps. The traces shown correspond to the following voltages: -70 (lowest trace), $-30,0,+20,+40$, and $+50 \mathrm{mV}$ (uppermost traces). Addition of DL-2-amino-5-phosphonopentanoic acid (DL-AP5, $50 \mu \mathrm{M}$ ) to the bath completely abolished the synaptic currents (inset). B, I-V relationship of the NMDA responses showing the characteristic " $\mathrm{J}$ " shape, with a region of negative slope conductance. The reversal potential estimated from the fit was $-2.1 \pm 7.3 \mathrm{mV}$ and peak inward current occurred near $-40 \mathrm{mV}(-38.7 \pm 4.2 \mathrm{mV})$. C. Plots of excitatory postsynaptic current rise time against the membrane potential. Note that the rise time tends to be faster with depolarization. $D$, Plot of the decay time constant against the membrane potential. The decay time constants are dependent on membrane voltage, being prolonged by depolarization in an exponential manner (increasing e-fold per $145 \mathrm{mV}$ ). The average at $-70 \mathrm{mV}$ differed significantly from that at $+50 \mathrm{mV}(\mathrm{P}<0.05$, Student $t$-test). 
$\pm 0.6 \mathrm{nS}(\mathrm{N}=5)$. The parameter $\delta$ in Equation 1 gives the fraction of membrane potential acting at the binding site or, in other words, the voltage dependence of the $\mathrm{Mg}^{2+}$ block. We found a value of $\delta$ equal to $0.7 \pm$ $0.2(\mathrm{~N}=5)$, and a value of $a$ equal to $10 \pm 4$ $\mathrm{mM}(\mathrm{N}=5)$ suggesting a weak $\mathrm{Mg}^{2+}$ block and that the $\mathrm{Mg}^{2+}$ blocking site is about $70 \%$ of the way across the membrane electrical field from the outside (but not necessarily $70 \%$ of the distance across the membrane, if the electrical field is not constant) (16). With the average values of $a$ and $\delta$ obtained from the fitting with Equation 1, the $\mathrm{K}_{\mathrm{D}}$ for $\mathrm{Mg}^{2+}$ in the NMDA receptor can be calculated by the following equation (16):

$\mathrm{K}_{\mathrm{D}}=\mathrm{a}^{*} \mathrm{e}^{\mathrm{V} \delta \mathrm{z} F / \mathrm{RT}}$

Eq. 4

We found a $\mathrm{K}_{\mathrm{D}}$ equal to $299 \pm 37 \mu \mathrm{M}(\mathrm{N}=5)$ at a holding potential of $-60 \mathrm{mV}$, a value relatively high, confirming the suggestion of a weak block of the NMDA receptors by $\mathrm{Mg}^{2+}$. It has been shown (19) that NMDA receptors containing NR2A or NR2B subunits have a much steeper voltage-dependence $(\boldsymbol{\delta} \sim 1)$ and pass maximal inward current at voltages close to $-25 \mathrm{mV}$. On the other hand, receptors containing NR2C or NR2D subunits show a weaker voltage-dependence $(\delta \sim 0.7)$ and pass maximal inward current at about $-35 \mathrm{mV}$. The maximal inward current obtained from our $I-V$ curve occurred at $-38.7 \pm 4.2 \mathrm{mV}$. Thus, these two parameters, $\delta$ and the voltage giving maximal inward current, suggest that the subpostremal NTS neurons contain subunits of the NR2C or NR2D type. The current response of NMDA receptors containing the NR2D subunit decays very slowly, with time constants of the order of $1 \mathrm{~s}$; NMDA receptors made up of NR2A subunits have fast kinetics, with decay time constants around $50 \mathrm{~ms}$, and those containing either the NR2B or NR2C sub- unit have decay time constants around 250$280 \mathrm{~ms}$ (20). In the present study, the decay phase of NMDA current was fitted with a single exponential function, with decay time constants of $239 \pm 50 \mathrm{~ms}$ at a holding potential of $-60 \mathrm{mV}$, and of $418 \pm 80 \mathrm{~ms}$ at +50 $\mathrm{mV}$. Taken together, the values of $\delta$, the voltage at which the inward current is maximal and the decay time constants, suggest the presence of NMDA receptors containing NR2C subunits in the subpostremal NTS. Because the intensity of NMDA receptor block by $\mathrm{Mg}^{2+}$ is relatively weak, this receptor can be activated at voltages close to the resting membrane potential $(-57 \pm 6.2 \mathrm{mV} ; \mathrm{N}$ $=65$ ), allowing depolarizing current to pass with significant amplitude. Since NMDAEPSCs have a slower decay phase than nonNMDA-EPSCs, Anchisi et al. (14) have shown that the charge transferred across the membrane by the NMDA receptor can be even larger than that transferred by the nonNMDA receptor. In our case, measurements in 4 cells showed that the total charge transferred during an EPSC (from the onset of the response to $520 \mathrm{~ms}$ later) at a holding potential of $-60 \mathrm{mV}$ (close to the resting membrane potential) was $11.9 \pm 2.4 \mathrm{pC}$. The isolated NMDA current was responsible for $6.5 \pm 1.3 \mathrm{pC}$, leaving $5.6 \pm 1.6 \mathrm{pC}$ for the non-NMDA component. These data indicate that in neurons of the subpostremal NTS, at the resting membrane potential, NMDA receptors pass about half of the total depolarizing charge of EPSC and may contribute to the generation of synaptic signals. The slow decay kinetics of the NMDA component, which was similar to that conferred by NR2C subunits $(19,20)$, could determine to a greater extent the temporal summation of synaptic signals. This suggests that the NMDA receptors in subpostremal NTS neurons operate not only as coincidence detectors but as integrators of synaptic input signals as well. 


\section{References}

1. Beckstead RM \& Norgren R (1979). An autoradiographic examination of the central distribution of the trigeminal, facial, glossopharyngeal and vagal nerves in the monkey. Journal of Comparative Neurology, 184: 455-472.

2. Loewy AD (1990). Central autonomic pathway. In: Loewy AD \& Spyer KM (Editors), Central Regulation of Autonomic Functions. Oxford, New York.

3. Barraco R, El-Ridi M, Ergene E, Parizon M \& Bradley D (1992). An atlas of the rat subpostremal nucleus tractus solitarius. Brain Research Bulletin, 29: 703-765.

4. Grabauskas G \& Bradley RM (2003). Frequency-dependent properties of inhibitory synapses in the rostral nucleus of the solitary tract. Journal of Neurophysiology, 89: 199-211.

5. Bonham AC \& Chen C (2002). Glutamatergic neural transmission in the nucleus tractus solitarius: N-methyl-D-aspartate receptors. Clinical and Experimental Pharmacology and Physiology, 29: 497-502.

6. Doyle MW \& Andresen MC (2001). Reliability of monosynaptic sensory transmission in brain stem neurons in vitro. Journal of Neurophysioloy, 85: 2213-2223.

7. Talman WT, Perrene MH \& Reis DJ (1980). Evidence for L-glutamate as the neurotransmitter of baroreceptor afferent nerve fibers. Science, 209: 813-815.

8. Aylwin ML, Horowitz JM \& Bonham AC (1997). NMDA receptors contribute to primary cisceral afferent transmission in the nucleus of the solitary tract. Journal of Neurophysiology, 77: 2539-2548.

9. Yen JW, Chan JYH \& Chan SHH (1999). Differential roles of NMDA and non-NMDA receptors in synaptic responses of neurons in nucleus tractus solitarius of the rat. Journal of Neurophysiology, 81: 3034-3043.

10. Nishi M, Hinds H, Lu H, Kawata M \& Hayashi $Y$ (2001). Motoneuron specific expression of NR3B, a novel NMDA-type glutamate recep- tor subunit that works in a dominant-negative manner. Journal of Neuroscience, 21: 1-6.

11. Dingledine R, Borges K, Bowie D \& Traynelis SF (1999). The glutamate receptor ion channels. Pharmacological Reviews, 51: 7-60.

12. Nowak L, Bregestovski $P$, Ascher $P$, Herbert A \& Prochiantz A (1984). Magnesium gates glutamate-activated channels in mouse central neurones. Nature, 307: 462-465.

13. Mayer ML, Westbrook GL \& Guthrie PB (1984). Voltage-dependent block by $\mathrm{Mg}^{2+}$ of NMDA responses in spinal cord neurones. Nature, 309: 261-263.

14. Anchisi D, Scelfo B \& Tempia F (2001). Postsynaptic currents in deep cerebellar nuclei. Journal of Neurophysiology, 85: 323-331.

15. O'Brien JA, Isaacson JS \& Berger AJ (1997). NMDA and non-NMDA receptors are co-localized at excitatory synapses of rat hypoglossal motoneurons. Neuroscience Letters, 227: 5-8.

16. Woodhull AM (1973). Ionic blockage of sodium channels in nerve. Journal of General Physiology, 61: 687-708.

17. Neher E \& Steinbach JH (1978). Local anaesthetics transiently block currents through single acetylcholine-receptor channels. Journal of Physiology, 277: 153-176.

18. Acher $P$ \& Nowak $L$ (1988). The role of divalent cations in the $N$ methyl-D-aspartate responses of mouse central neurones in culture. Journal of Physiology, 399: 247-266.

19. Kuner T \& Schoepfer S (1996). Multiple structural elements determine subunit specificity of $\mathrm{Mg}^{2+}$ block in NMDA receptor channels. Journal of Neuroscience, 16: 3549-3558.

20. Vicini S, Wang JF, Li JH, Zhu WJ, Wang YH, Luo JH, Wolfe BB \& Grayson DR (1988). Functional and pharmacological differences between recombinant $\mathrm{N}$-methyl-D-aspartate receptors. Journal of Neurophysiology, 79: 555-566. 